\title{
Iron supplemented formula milk prevented iron deficiency anaemia and reduced developmental declines in infants from inner city areas
}

Williams J, Wolff A, Daly A, et al. Iron supplemented formula milk related to reduction in psychomotor decline in infants from inner city areas: randomised study. BMJ 1999 Mar 13;318:693-7.

QUESTION: Does iron supplemented formula milk, compared with unmodified cows' milk, prevent iron deficiency anaemia and improve psychomotor developmental outcomes in infants from an inner city area?

\section{Design}

Randomised \{allocation concealed\}*, blinded (outcome assessor), controlled trial with follow up at age 24 months.

\section{Setting}

An inner city area of Birmingham, UK. The area was described as socially deprived, with high unemployment, poor housing, and poor public amenities.

\section{Patients}

100 full term infants (mean age $7.8 \mathrm{mo}, 53 \%$ girls, $75 \%$ white) identified by health visitors working in the area, whose mothers had already changed their infant's diet to unmodified cows' milk. Follow up was $85 \%$ at 24 months.

\section{Intervention}

50 infants were allocated to iron supplemented formula milk (1.2 mg iron/100 ml) until 18 months of age and then were switched back to unmodified cows' milk until 24 months of age. 50 infants were allocated to continue on unmodified cows' milk $(0.05 \mathrm{mg}$ iron/100 ml) until 24 months of age.

\section{Main outcome measures}

Mean haemoglobin concentration; overall developmental score assessed using the Griffiths scale (mean of 5 subscale scores: locomotor, personal and social, hearing and speech, eye and hand coordination, and performance [manipulation and precision]); and developmental scores for subscales.

\section{Main results}

At 24 months, none of the infants who received iron supplemented formula milk was anaemic (even after switching back to unmodified cows' milk at 18 months) compared with $26 \%$ of infants who received unmodified cows' milk only $(\mathrm{p}<0.002)$. Overall developmental scores declined in both the iron supplemented formula group and the unmodified cows' milk group; however, the iron supplemented formula group had a smaller decrease than the cows' milk formula group (decrease of $9.3 v 14.7$ points; difference of 5.4 points, $95 \%$ CI around the difference $0.4 \%$ to $10.4 \%$ ). The iron supplemented formula group also had smaller decreases in subscale scores for personal and social development (decrease of $10.0 v 19.0$; difference of 9.0 points, CI around the difference 1.2 to 16.8 ).

\section{Conclusion}

Among infants from an inner city area, iron supplemented formula milk given from 6 to 18 months of age prevented iron deficiency anaemia and led to smaller declines in overall developmental functioning at 24 months of age than unmodified cows' milk.
*Information provided by author.

\section{COMMENTARY}

About $10 \%$ of pre-school children in developed countries many of whom are socioeconomically deprived, are iron deficient. ${ }^{1}$ Evidence exists of an association between iron deficiency anaemia and developmental delay. ${ }^{2}$ The study by Williams et al adds to the debate about the efficacy of supplementing infant formula with iron to improve haematological and developmental outcomes of infants. In this study, families of infants from inner city areas received iron supplemented formula milk free of charge (intervention group) or a monthly payment equivalent to the cost of 500 $\mathrm{ml}$ of cows' milk each day (control group). However, there does not appear to have been any monitoring of whether the monthly payment was indeed used to buy milk.

The results of recent studies vary in their support of positive infant haematological and developmental outcomes resulting from iron supplementation..$^{23}$ The inconsistency of findings may be because of the small sample sizes used in several studies or methodological weaknesses, such as large losses to follow up. ${ }^{4}$ Future studies should be larger and should pay closer attention to the amount and schedule of the assigned infant feeding, assessment of overall infant diet, consideration of social influences that might affect developmental outcomes, and more frequent measurement of outcomes.

As nurses, we must keep in mind that, nutritionally and economically, breast milk is the milk of choice for infants, and we should encourage more research into the evaluation of interventions to promote breast feeding. In cases where breast feeding is not possible, the following information about iron deficiency anaemia is important. Firstly, iron deficiency anaemia is common in socioeconomically deprived infants; secondly, there appears to be an association between iron deficiency anaemia and developmental delay; and thirdly, pending the results of larger trials, an iron supplemented formula for infants who are not receiving breast milk may prevent anaemia and reduce declines in developmental performance.

\section{Carolyn Spence Cagle, RNC, PhD Associate Professor Texas Christian University Fort Worth, Texas, USA}

1 DeMaeyer E, Adiels-Tegman M. The prevalence of anaemia in the world. World Health Stat Q 1985;38:302-16.

2 Idjradinata P, Pollitt E. Reversal of developmental delays in iron-deficient anaemic infants treated with iron. Lancet 1993;341:1-4.

3 Moffatt ME, Longstaffe S, Besant J, et al. Prevention of iron deficiency and psychomotor decline in high-risk infants through use of iron-fortified infant formula: a randomised clinical trial. J Pediatr 1994;125:527-34.

4 Logan S. Commentary: iron deficiency and developmental deficit: the jury is still out. BMJ 1999;318:697-8. 